\title{
Diversity of bacterial community during ensiling and subsequent exposure to air in whole-plant maize silage
}

\author{
Zongfu Hu${ }^{1,2}$, Jie Chang ${ }^{1}$, Jianhua $\mathrm{Yu}^{1}$, Shuguo $\mathrm{Li}^{1}$, and Huaxin $\mathrm{Niu}^{1, *}$
}

* Corresponding Author: Huaxin Niu Tel: +86-0475-8314845, Fax: +86-0475-8314845,

E-mail: niuhx@imun.edu.cn

${ }^{1}$ College of Animal Science and Technology, Inner Mongolia University for Nationalities, Tongliao 028000, China

${ }^{2}$ Inner Mongolia Key Laboratory of Toxicant Monitoring and Toxicology, Tongliao, China

ORCID

Zongfu Hu

https://orcid.org/0000-0002-1904-7082 Jie Chang

https://orcid.org/0000-0001-6773-4824 Jianhua Yu

https://orcid.org/0000-0002-5594-5971

Shuguo Li

https://orcid.org/0000-0002-1162-5829

Huaxin Niu

https://orcid.org/0000-0002-1047-6139

Submitted Nov 23, 2017; Revised Feb 9, 2018; Accepted Apr 18, 2018
Objective: To describe in-depth sequencing, the bacterial community diversity and its succession during ensiling of whole-plant maize and subsequent exposure to air.

Methods: The microbial community dynamics of fermented whole-plant maize for 60 days (sampled on day 5, 10, 20,40,60) and subsequent aerobic exposure (sampled on day 63 after exposure to air for 3 days) were explored using Illumina Miseq sequence platform.

Results: A total of 227,220 effective reads were obtained. At the genus level, there were 12 genera with relative abundance $>1 \%$, Lactobacillus, Klebsiella, Sporolactobacillus, Norank-ccyanobacteria, Pantoea, Pediococcus, Rahnella, Sphingomonas, Serratia, Chryseobacterium, Sphingobacterium, and Lactococcus. Lactobacillus consistently dominated the bacterial communities with relative abundance from $49.56 \%$ to $64.17 \%$ during the ensiling process. Klebsiella was also an important succession bacterium with a decrease tendency from $15.20 \%$ to $6.41 \%$ during the ensiling process. The genus Sporolactobacillus appeared in late-ensiling stages with $7.70 \%$ abundance on day 40 and $5.32 \%$ on day 60 . After aerobic exposure, the Lactobacillus decreased its abundance from $63.2 \%$ on day 60 to $45.03 \%$ on d 63 , and Klebsiella from $5.51 \%$ to $5.64 \%$, while Sporolactobacillus greatly increased its abundance to $28.15 \%$. These bacterial genera belong to 5 phyla: Firmicutes (relative abundance: $56.38 \%$ to $78.43 \%$ ) was dominant, others were Proteobacteria, Bacteroidetes, Cyanobacteria, and Actinobacteria. The bacterial communities clearly clustered into early-ensiling (d 5), medium-ensiling (d 10, d 20), lateensiling (d 40, d 60), and aerobic exposure (d 63) clusters, with early- and late-ensiling communities more like each other than to the aerobic exposure communities.

Conclusion: High-throughput sequencing based on 16S rRNA genes proved to be a useful method to explore bacterial communities of silage. The results indicated that the bacterial communities varied during fermentation and more dramatically during aerobic exposure. The study is valuable for understanding the mechanism of population change and the relationship between bacteria and ensilage characteristics.

Keywords: High-through Sequence; Bacterial Community; Diversity; Lactic Acid Bacteria; Whole-plant Maize Silage

\section{INTRODUCTION}

The rapid growth of meat and milk production in China requires development of an efficient silage industry. Maize straw is an important feed resource for ruminants. In the north of China, such as Inner Mongolia, it is not only a main base for milk, beef and mutton production, but also a main production base of maize. Many of silage maize variety are cultivated for ruminants feed.

Ensiled silage has the benefit of preventing loss in nutrition value and can keep well throughout a year or more. The essence of the silage is that lactic acid bacteria (LAB) multiply in the anaerobic environment and produce lactate which drops the $\mathrm{pH}$ to below 4.0. The low $\mathrm{pH}$ in turn prevents or restrains the growth of other infectious microbes. 
Microbial succession in food fermentation or silage has been previously studied. For instance, Zheng et al [1] examined microbial community dynamics of ensiling alfalfa Medicago sativa and found that Lactobacillus dominated the whole process of ensiling like the dynamics patterns of ensiling reported by McGarvey et al [2]. Li et al [3] reported the bacterial community succession in Vicia faba fermentation persisted for 77 days using MiSeq analysis base $16 \mathrm{~S}$ rRNA genes. Yang et al [4] used $16 \mathrm{~S}$ rRNA sequences to report the bacterial community diversity and dynamics for 15 days fermentation of douchi sauce. For maize ensiling, Lin et al [5] reported dominant establishment of lactobacillus in early stages of maize ensiling ( 1 to 7 days). Subsequent studies by Zhou et al [6] also demonstrated the dominant position of lactobacillus after 60 days of ensiling in whole-plant corn silage.

However, research on maize silage production has mainly used culture-dependent methods or denaturing gradient gel electrophoresis (DGGE) [5-7], and lack using new techniques such as high-through sequence which can give a full-scale insight into the microbial community without culture-dependent process. In this study, we used Illumina MiSeq to describe the bacterial community dynamics during ensiling of whole-plant maize; this will enlighten the understanding of the dynamic process of bacterial community during the fermentation of maize.

\section{MATERIALS AND METHODS}

\section{Dealing of samples}

Raw maize samples were collected from a local meadow named Chajintai in Kerzuozhong County $\left(\mathrm{E} 122^{\circ} 15^{\prime}, \mathrm{N} 43^{\circ} 38^{\prime}\right)$, Inner Mongolia, China, on Oct 8, 2016. The fresh maize was harvested by combine-harvester $20 \mathrm{~cm}$ from ground and chopped into 1 to $2 \mathrm{~cm}$ in lengths and immediately transported to the laboratory for processing. Three kilograms of the chopped maize material was compressed and sealed in 18 polyethylene silo bags (Hiryu $\mathrm{KN}$ type, $400 \times 600 \mathrm{~mm}$, Asahikasei, Tokyo, Japan) using a vacuum sealer (BH 950, Matsushita, Tokyo, Japan) for air removal. The silo bags were stored at room temperature $\left(25^{\circ} \mathrm{C}\right)$. Samples were taken from three bags per timing at $5,10,20,40,60$, and 63 days (the bags were opened for exposure to air at day 60 and lasted for 3 days), respectively, and divided into two portions. One part was sampled in 50 $\mathrm{mL}$ cryogenic vials and stored in $-80^{\circ} \mathrm{C}$ for $16 \mathrm{~S}$ rRNA gene amplicons sequencing, and another was stored in $-20^{\circ} \mathrm{C}$ for biochemical analysis.

\section{Chemical analyses}

The dry matter (DM) content of silage samples was determined by drying $100 \mathrm{~g}$ of samples collected on each sampling day at $65^{\circ} \mathrm{C}$ for $48 \mathrm{~h}$ in a dry oven [8]. The $\mathrm{pH}$ value was measured as follows: $10 \mathrm{~g}$ of silage was mixed with $90 \mathrm{~mL}$ of deionized water and shaken for $5 \mathrm{~min}$ every other $50 \mathrm{~min}$, after $3 \mathrm{~h}$, the $\mathrm{pH}$ value of filtrate form silage was measured by electrode $\mathrm{pH}$ meter (S20K, Mettler Toledo, Greifensee, Switzerland). Concentrations of lactic acid and acetic acid were measured in high performance liquid chromatography (1100, Agilent, Palo Alto, CA, USA) fitted with a UV detector $(210 \mathrm{~nm})$ and a column (ICSep COREGEL-87H, Transgenomic, Inc., New Haven, CT, USA). The mobile phase was $0.005 \mathrm{M} \mathrm{H}_{2} \mathrm{SO}_{4}$ at a flow rate of $0.6 \mathrm{~mL} / \mathrm{min}$ at $55^{\circ} \mathrm{C}$ [9]. Fifteen grams of fresh forage or silage at each sampling day was combined with $135 \mathrm{~g}$ of de-ionized $\mathrm{H}_{2} \mathrm{O}$, blended for $30 \mathrm{~s}$ and strained through four layers of cheesecloth. The liquid fraction was sampled and analyzed for and ammonia $\mathrm{N}\left(\mathrm{NH}_{3}-\mathrm{N}\right)$ as described by Zahiroddini et al [10].

\section{DNA extraction of the microbial community}

The fermented maize straw was sampled ( $20 \mathrm{~g}$ for each bag) and quickly frozen at $-80^{\circ} \mathrm{C}$ for DNA extraction. Silage $(20 \mathrm{~g})$ was homogenized with distilled water $(80 \mathrm{~mL})$, then filtered through two layers of medical gauze and centrifuged for 15 $\min$ at $10,000 \mathrm{~g}$ at $4^{\circ} \mathrm{C}$.

Triplicate samples of centrifuge production were dissolved and blended together. DNA was extracted using the FastDNA SPIN Kit for Soil (MP Biomedicals, Santa Ana, CA, USA), according to the manufacturer's instructions [11]. The DNA quality was checked by $1 \%$ agarose gel electrophoresis and spectrophotometer (NanoDrop2000, Thermo Scientific, Waltham, MA, USA, optical density at $260 \mathrm{~nm} / 280 \mathrm{~nm}$ ratio).

\section{Polymerase chain reaction amplification of target region}

Primers 338F (ACTCCTACGGGAGGCAGCA) and 806R (GGACTACHVGGGTWTCTAAT) [12] both with 12 bps barcodes were used to amplify the V3-4 hyper-variable region of the bacterial $16 \mathrm{~S}$ rRNA gene. The sequences were assigned to their respective samples according to their barcodes of primers. The polymerase chain reaction (PCR) amplification of bacterial 16S rRNA V3-4 region was performed as described in TransStart FastPfu system (Transgen Biotech Company, Beijing, China) [13]. The PCR cycle conditions were the following: an initial denaturation at $95^{\circ} \mathrm{C}$ for $3 \mathrm{~min}, 27$ cycles of $95^{\circ} \mathrm{C}$ for $30 \mathrm{~s}, 55^{\circ} \mathrm{C}$ for $30 \mathrm{~s}$, and $72^{\circ} \mathrm{C}$ for $45 \mathrm{~s}$, and a final extension at $72^{\circ} \mathrm{C}$ for $10 \mathrm{~min}$. Each $20 \mu \mathrm{L}$ reaction mixture consisted of $4.0 \mu \mathrm{L}$ of $5 \times$ FastPfu Buffer, $2 \mu \mathrm{L}$ of deoxynucleoside triphosphate mix (2.5 mM each), $0.4 \mu \mathrm{L}$ of FastPfu DNA Polymerase, $10 \mathrm{ng}$ of template DNA, $0.8 \mu \mathrm{L}$ of Forward Primer $338 \mathrm{~F}(5 \mu \mathrm{M})$, $0.8 \mu \mathrm{L}$ of Forward Primer $806 \mathrm{R}(5 \mu \mathrm{M}), 0.2 \mu \mathrm{L}$ of bovine serum albumin, and others of double-distilled $\mathrm{H}_{2} \mathrm{O}$.

\section{Library preparation and sequencing}

NEB Next Ultra DNA Library Prep Kit for Illumina (New England Biolabs Inc., Ipswich, MA, USA) was used to generate 
sequencing libraries according to the manufacturer's instructions. The library quality was assessed by spectrophotometry and then sequenced on Illumina Miseq PE300 platform (Illumina Corporation, San Diego, CA, USA) at the Shanghai Majorbio Bio-Pharm Technology co., Ltd. (Shanghai, China).

\section{Bioinformatics analysis of sequencing data}

The operational taxonomic units (OTUs) clustering used Usearch (vsesion $7.1 \mathrm{http}: / /$ drive5.com/uparse/) [14] at a 97\% identity threshold to create OUTs table. The OUTs representing sequences were compared with data online Silva (Release123 http://www.arb-silva.de) and used RDP classifier Naive Bayes (version $2.2 \mathrm{http}: / /$ sourceforge.net/projects/rdp-classifier/) to obtain species taxonomy information [15].

Rarefaction curves and alpha-diversity indices were calculated by software Mothur (version v.1.30.1 http://www. mothur.org/wiki/Schloss_SOP\#Alpha_diversity) [16]. The cluster analysis of sample hierarchy used Qiime platform (http:// qiime.org/scripts/assign_taxonomy.html), $\mathrm{R}$ language was used to determine beta diversity. Venn figures were calculated by $\mathrm{R}$ language, and Heat maps analysis was performed by $\mathrm{R}$ language vegan package [17].

\section{Statistical analysis}

All results are reported as the mean \pm standard error of three replicate groups, and data were subjected to one-way analysis of variance. When there were significant differences $(p<0.05)$, the group means were further compared with Duncan's multiple range tests. All statistical analyses were performed using
SPSS 17.0 (SPSS, Chicago, IL, USA).

\section{RESULTS}

\section{Chemical analysis of whole-plant maize ensiling} The DM content of silages slightly declined during ensiling. The $\mathrm{pH}$ dropped from 4.10 in sample $\mathrm{d} 5$ to about 3.8 in $\mathrm{d} 10$ to $\mathrm{d} 60$ samples, and slightly increased to 3.91 after exposure to air for 3 days (Table 1). The lactic acid content showed increasing tendency during ensiling. Silage from d 20 to d 63 samples had higher lactic acid content than $\mathrm{d} 5$ to $\mathrm{d} 10 \mathrm{sam}$ ples. Compared to $\mathrm{d} 60$, the lactic acid content of sample $\mathrm{d}$ 63 showed a non-significant decrease. Acetic acid at low level in $\mathrm{d} 5$ and $\mathrm{d} 10$ samples, significantly increased to about 16.80 $\mathrm{mg} / \mathrm{g}$ DM in $\mathrm{d} 40$ and $\mathrm{d} 60$ samples, and then increased remarkably to about $23.78 \mathrm{mg} / \mathrm{g}$ DM in d 63 sample. The ammonia nitrogen slightly increased during ensiling and subsequently during aerobic exposure. The level of ammonia nitrogen in d 5, d 10, and d 20 samples was lower than sample d 40, d 60, and $\mathrm{d} 63$.

\section{Sequence analysis and alpha-diversity of bacterial community}

A total of 227,220 valid reads were obtained from the 6 merged samples (Table 2), with an average of $37,870 \pm 6,425$ reads per sample, and the mean length of the target sequences were 447.5 bps (Table 2). After quality control, the sequence with chimera and single sequence OTUs were eliminated, and the high quality sequences of 206,842 were obtained, with an average

Table 1. The fermentation quality and nutrient composition of the whole maize silage ${ }^{1)}$

\begin{tabular}{|c|c|c|c|c|c|c|}
\hline Items & d 5 & d 10 & d 20 & d 40 & d 60 & d 63 \\
\hline DM (\% DM) & $32.57 \pm 3.13^{\mathrm{a}}$ & $32.73 \pm 1.26^{\mathrm{a}}$ & $31.83 \pm 1.68^{\mathrm{a}}$ & $31.05 \pm 0.46^{b}$ & $31.73 \pm 2.22^{a}$ & $31.17 \pm 0.76^{\mathrm{ab}}$ \\
\hline $\mathrm{pH}$ & $4.10 \pm 0.41^{\mathrm{a}}$ & $3.88 \pm 0.23^{b}$ & $3.82 \pm 0.09^{b}$ & $3.76 \pm 0.42^{b}$ & $3.83 \pm 0.08^{b}$ & $3.91 \pm 0.10^{a}$ \\
\hline LA (mg/g DM) & $48.37 \pm 2.14^{b}$ & $56.55 \pm 6.10^{b}$ & $88.19 \pm 7.35^{\mathrm{a}}$ & $96.9 \pm 3.83^{\mathrm{a}}$ & $96.9 \pm 2.66^{a}$ & $90.84 \pm 4.27^{\mathrm{a}}$ \\
\hline $\mathrm{AA}(\mathrm{mg} / \mathrm{g} \mathrm{DM})$ & $4.79 \pm 0.32^{c}$ & $5.08 \pm 0.02^{c}$ & $9.46 \pm 1.72^{c}$ & $16.53 \pm 2.02^{b}$ & $16.87 \pm 3.27^{b}$ & $23.78 \pm 4.14^{a}$ \\
\hline $\mathrm{NH}_{3}-\mathrm{N}(\mathrm{mg} / \mathrm{g} \mathrm{DM})$ & $0.51 \pm 0.02^{b}$ & $0.59 \pm 0.05^{b}$ & $0.72 \pm 0.05^{\mathrm{ab}}$ & $0.92 \pm 0.02^{\mathrm{a}}$ & $0.91 \pm 0.11^{\mathrm{a}}$ & $0.97 \pm 0.07^{\mathrm{a}}$ \\
\hline
\end{tabular}

$\mathrm{DM}$, dry matter; $\mathrm{LA}$, lactic acid; $\mathrm{AA}$, acetic acid; $\mathrm{NH}_{3}-\mathrm{N}$, ammonia nitrogen.

1) The sample name $d 5$ indicates the silage was sample on 5 days after ensiling; the same as $d$ 10, $d 20, d$ 40, d 60, but $d 63$ was sampled on 3 days after open the silo from d 60, the same as below diagram.

abc Mean values with different superscripts with in a row differ significantly, $p<0.05$.

Table 2. The sequencing index of samples based on 165 rRNA gene ${ }^{1)}$

\begin{tabular}{|c|c|c|c|c|c|c|c|c|c|}
\hline Sample & Valid sequence & High quality sequence & OUTs & OUTs $>1 \%$ & Ace & Coverage & Shannon & Simpson & Sobs \\
\hline d 5 & 34,175 & 30,149 & 253 & 12 & 293.1 & 0.9984 & 2.973 & 0.1224 & 253 \\
\hline d 10 & 34,508 & 31,243 & 208 & 15 & 228.0 & 0.9990 & 2.686 & 0.1555 & 208 \\
\hline d 20 & 39,423 & 35,410 & 247 & 14 & 282.3 & 0.9987 & 2.662 & 0.1646 & 247 \\
\hline d 40 & 43,901 & 38,658 & 263 & 9 & 288.1 & 0.9987 & 2.682 & 0.1490 & 263 \\
\hline$d 60$ & 30,918 & 29,476 & 313 & 11 & 334.1 & 0.9986 & 2.822 & 0.1508 & 313 \\
\hline$d 63$ & 44,295 & 42,006 & 295 & 9 & 327.8 & 0.9992 & 2.641 & 0.1702 & 295 \\
\hline
\end{tabular}

OTUs, operational taxonomic units.

1) Calculations were performed based on the OTU definition at $>97 \%$ sequence identity. 
of $34,490 \pm 7,515$ reads per sample. For limiting the sampling error, we sub-sampled all of the six samples to 29,300 sequences. All these reads were clustered into 357 OTUs based on $97 \%$ sequence identity, and these OUTs were assigned to 295 species, 207 genera, 115 families, 71 orders, 34 classes, and 17 phyla. The OTUs number with abundance $>1 \%$ were at the range of 9 to 15 different with samples (Table 2). With the number of samples increasing, the number of OUTs in all samples increased from about 262 to 357 , while the core OUTs decreased from 261 to 146 with a ratio of 40.9\% (146/357). Richness accumulated observed (Sobs) and abundance based coverage estimator (Ace) showed the slight increase in richness of the bacterial community in ensiling [4,18]. Good's coverage of all the samples was above 0.99 [1], the curves of Shannon and rarefaction flattened [2], indicating that the sequence quantity was adequate and covered almost all of bacteria in the samples.

\section{Cluster analysis of bacterial community}

The principal coordinate analysis based on weighted unifrac provided four clusters clearly separated in relation to the ensiling time (Figure 1). Sample from d 5 were clustered as an early-ensiling cluster. Sample from d 10 and d 20, were clustered as a midterm-ensiling cluster. The third cluster, including samples from $\mathrm{d} 40$ and $\mathrm{d} 60$, were grouped as a late-ensiling cluster. The fourth cluster, including d 63 sample alone was clustered as aerobic exposure cluster.

\section{Bacterial succession during ensiling process and exposure stage}

Changes in the bacterial community during ensiling are presented in Figure 2. At the phylum level, bacterial communities in all samples were dominated by Firmicutes (relative abundance: $57.31 \%$ to $78.40 \%$ ) and Proteobacteria (relative abundance: $31.02 \%$ to $16.94 \%$ ), others were Bacteroidetes (relative abundance: $6.48 \%$ to $2.26 \%$ ), Cyanobacteria (relative abundance: $6.97 \%$ to $1.23 \%$ ), Actinobacteria (relative abundance: $1.14 \%$ to $1.98 \%)$, Chloroflexi.

At genus level, there were 12 genera shared by all of merged samples with $>1 \%$ relative abundance, namely Lactobacillus, Klebsiella, Sporolactobacillus, C-cyanobacteria, Pantoea, Pediococcus, Rahnella, Sphingomonas, Serratia, Chryseobacterium, Sphingobacterium, and Lactococcus (Figure 2).

At the early stage of ensiling in sample $\mathrm{d} 5$, the most abundant reads were Lactobacillus (49.57\%), followed by Klebsiella (9.03\%) (Figure 2). The class Cyanobacteria has the abundance of $6.97 \%$ which could not be classified to genus level. Other genera with $>1 \%$ abundance were Chryseobacterium (3.12\%), Pediococcus (3.16\%), Rahnella (3.01\%), Lactococcus (2.63\%), Sphingomonas (2.34\%), Enterobacter (2.26\%), Pantoea (1.47\%), Serratia (1.11\%), and Sphingobacterium (1.3\%).

Changes occurred during the ensiling process. In the sample

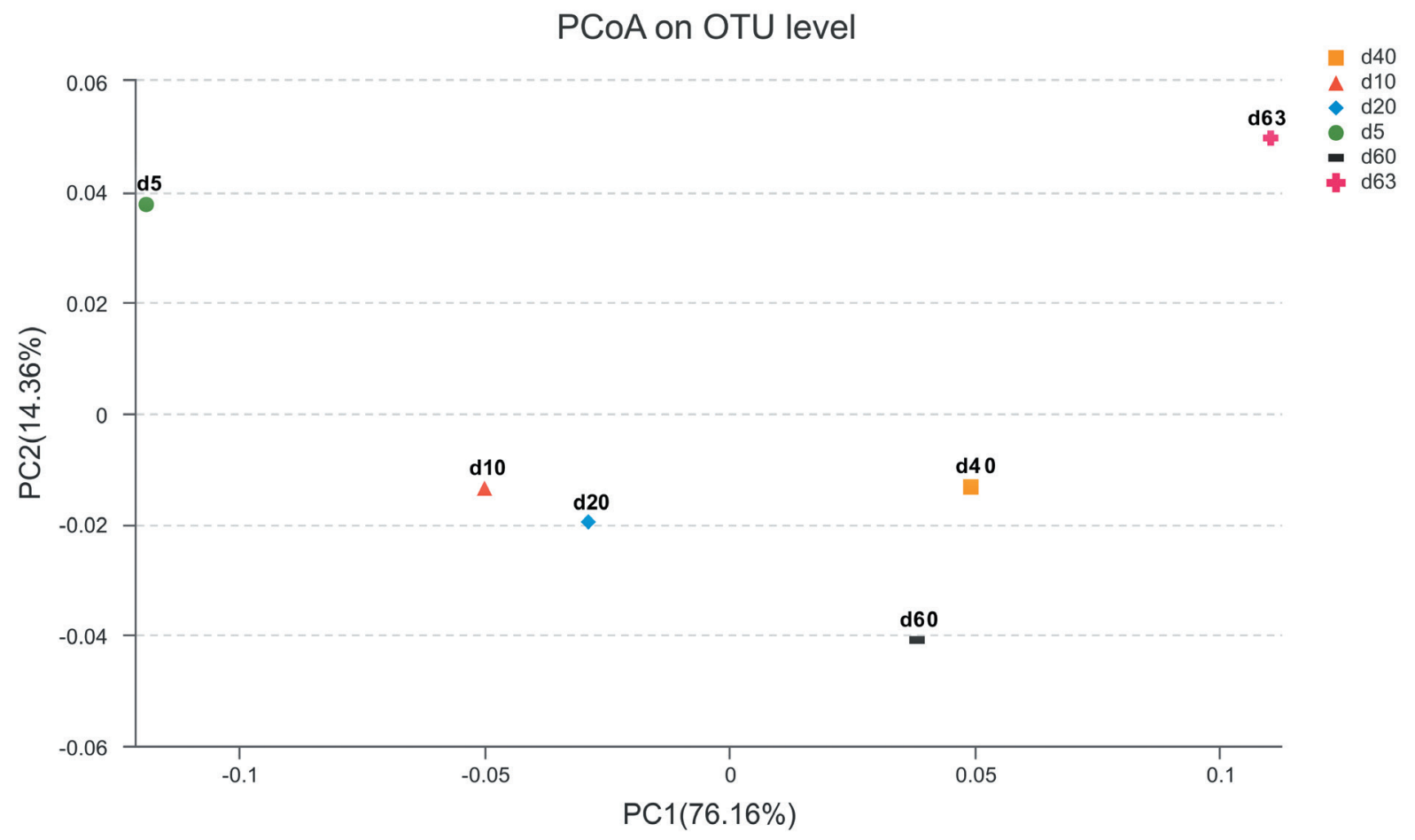

Figure 1. PcoA analysis of the silage bacterial community based on Weighted Unifrac distance. The Weighted Unifrac distance considers both the presence/absence of OTUs and relative abundance of OTUs. Each point represents a silage sample with different color and shape. The first principal component (PC1) is plotted on the X-axis, the second principal component (PC2) is plotted on the Y-axis. PcoA, Principal coordinate analysis; OTUs, operational taxonomic units. 


\section{Community barplot analysis}
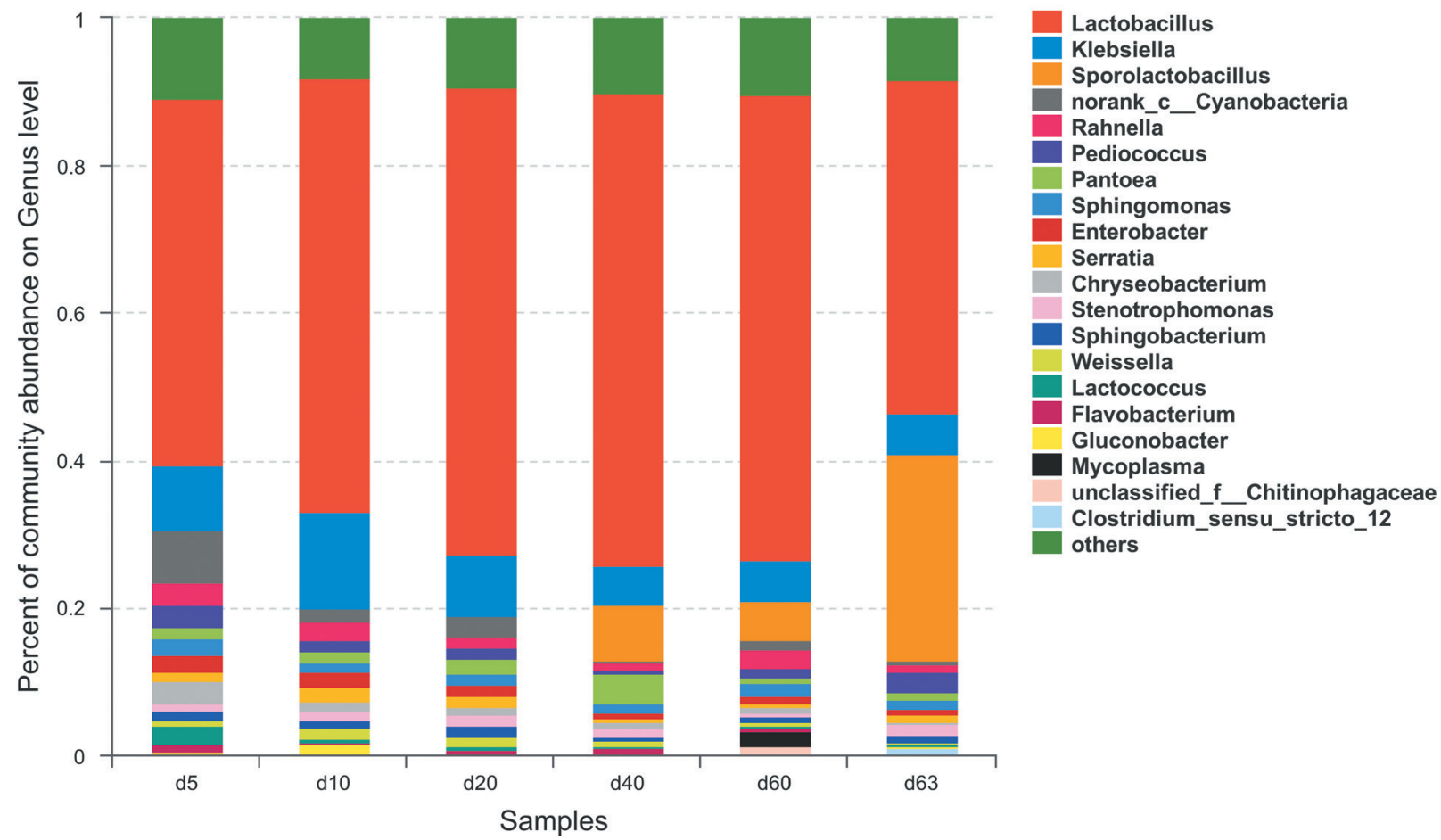

Figure 2. Relative abundance of bacterial community in maize silage during ensiling and air exposure periods at genus level. X-axis represents sample day, Y-axis represents the relative abundance. Genera with abundance lower than $1 \%$ in samples were not shown. The genera could not be assigned were marked as 'unclassified' or 'norank', then they were assigned at family level or up one or more levels.

stage of d 10, Lactobacillus increased its abundance to $58.62 \%$, and Klebsiella increased to $13.34 \%$ (Figure 2). Others with $>1 \%$ abundance also varied or disappeared, such as Lactococcus, while some appeared in $>1 \%$ abundance, such as Weissella (1.47\%), Gluconobacter (1.52\%), and Stenotrophomonas (1.30\%).

During the ensiling process Lactobacillus increased in abundance to at $64.1 \%$ in the $\mathrm{d} 40$ sample (Figure 2). Klebsiella decreased to $5.29 \%$ in the $\mathrm{d} 40$ sample. Conspicuous changes appeared in Sporolactobacillus, which first occurred in the d 40 sample at $7.70 \%$ abundance and $5.32 \%$ in the $\mathrm{d} 60$ sample. At the $\mathrm{d} 40$ stage, the samples had the highest level of LAB Lactobacillus, and the lowest genera number (7 genera: Lactobacillus, Klebsiella, Stenotrophomonas, Sporolactobacillus, Flavobacterium, Pantoea, and Sphingomonas) with $>1 \%$ abundance. At d 60 stage, the genus Lactobacillus had slightly decreased in abundance (63.2\%) as well as Klebsiella (5.51\%). Mycoplasma first occurred with abundance of $2.02 \%$. The class Cyanobacteria which disappeared in $\mathrm{d} 40$ occurred again in $\mathrm{d} 60$.

The 3-day aerobic exposure of the $\mathrm{d} 60$ samples (d 63), greatly impacted the ensiling. The genus Lactobacillus decreased to $45.03 \%$, the decrease proportion was up to $29.76 \%$ compared to d 60 (Figure 2). The genus Sporolactobacillus greatly increased to $28.15 \%$, the increase proportion was up to $429.14 \%$ compared to $\mathrm{d} 60$. The genus Klebsiella stabilized at an abun- dance of 5.6\%. Other genera with low abundance at this stage were Sphingomonas (1.16\%), Pediococcus (2.88\%), Rahnella (1.13\%), Serratia (1.09\%), and Stenotrophomonas (1.43\%).

The most concern in silage is the appearance of harmful bacteria, such as Clostridium and Mycoplasma. During the ensiling process, there was good control of these harmful bacteria, Mycoplasma only appeared in the d 60 sample with an abundance of $2.02 \%$ and no Clostridium ever appeared. But at the aerobic exposure stage, the Clostridium appeared at an abundance of $1.06 \%$ (Figure 2).

\section{The core bacterial community during ensiling process and exposure stage}

There were 146 core bacterial species (OTUs) existing in all samples from the ensiling process to the aerobic exposure stage, occupying the proportion of $40.89 \%$ of all 357 OTUs. At genus level, they were Lactobacillus, Klebsiella, Pediococcus, Sphingomonas, Serratia, Rahaella, Pantoea, Sphingobacterium, Stenotrophomonas, Weissella, Chryseobacterium, and Acinetobacter, et al. The occurrence of core bacterial community also can be demonstrated by Heatmap analysis (Figure 3).

The bacterial Lactobacillus showed its persistent domination at all stages with abundance $49.57 \%, 58.62 \%, 63.24 \%$, $64.11 \%, 63.20 \%$, and $45.03 \%$ in samples $\mathrm{d}$ 5, d 10, d 20, d 40, $\mathrm{d} 60$, and $\mathrm{d} 63$ respectively (Figure 2 ), increasing during en- 


\section{Community heatmap}

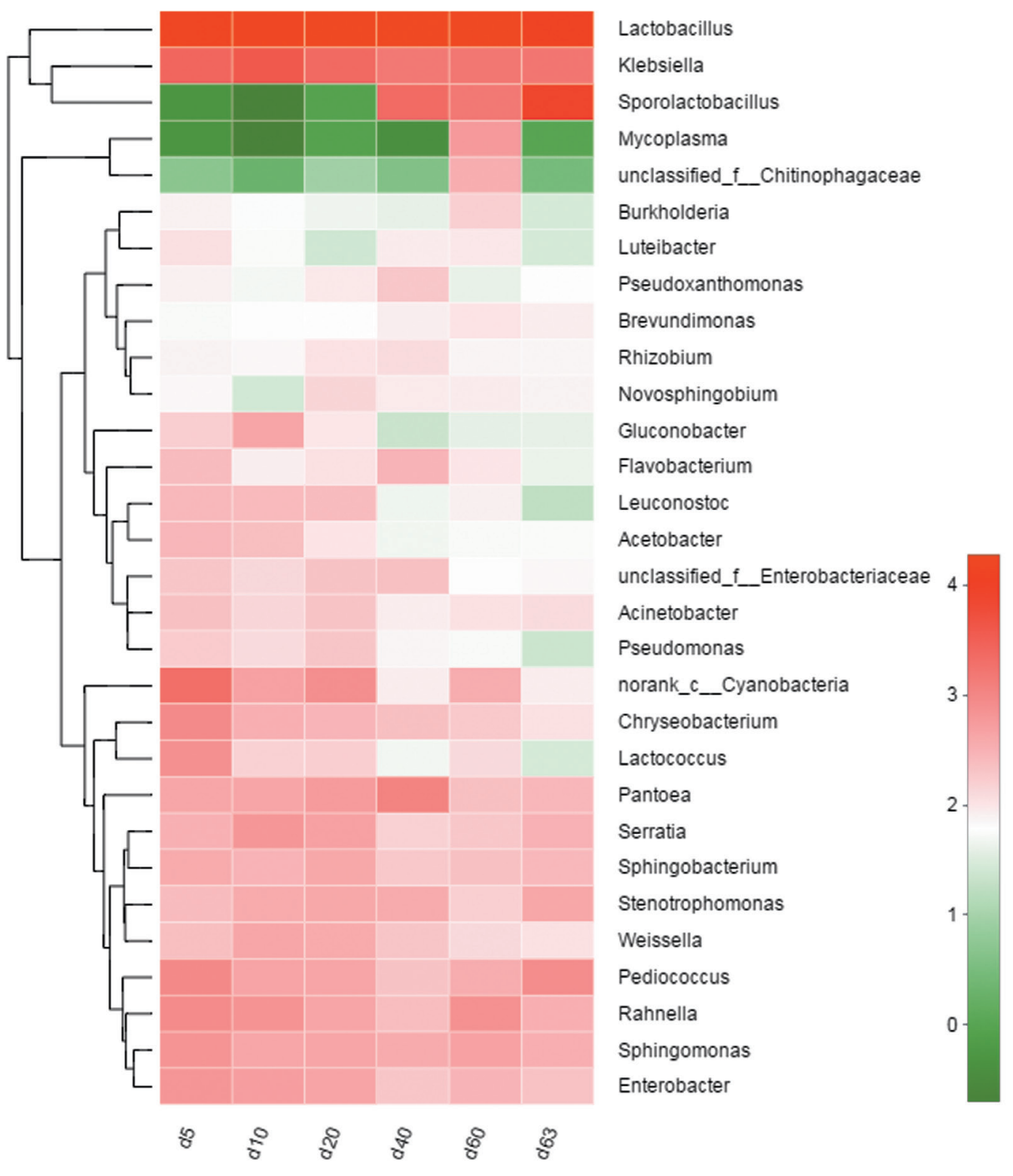

Figure 3. Heatmap analysis of top 30 genera according to relative abundance. $X$-axis represents sample name, Y-axis represents the genus. Block with red color indicates the high abundance of the genus, the green block indicates the low abundance of the genus. The Hierarchical clustering tree appears on the upside of block while the phylogenetic tree appears on the left side of block.

siling, but greatly decreased at the aerobic exposure stage ( $d$ 63) $(\mathrm{p}<0.001)$ (Figure 5). The bacteria Lactobacillus consisted of L. plantarum, L. brevis and L. crustorum mainly, but the abundance of $L$. plantarum reduced after aerobic exposure (Figure 4). The abundance of Klebsiella was 9.03\%, 13.34\%, $8.04 \%, 5.29 \%, 5.51 \%$, and $5.64 \%$ in samples d 5, d 10, d 20, d $40, \mathrm{~d} 60$, and $\mathrm{d} 63$ respectively (Figure 2), increasing at the early stages ( $\mathrm{d} 5$ to $\mathrm{d} 10)$ and decreasing at the later stages. Sporolactobacillus occurred at the late stages of ensiling and exposure stage with abundance of $7.7 \%$ (d 40), 5.32\% (d 60), 28.15\% (d 63), the increase at exposure stage was highly significant $(\mathrm{p}<0.001)$ (Figure 5).

\section{DISCUSSION}

Compared to extensive work with culture-dependent methods and LAB-focusing [19-21], advanced molecular techniques could better demonstrate the bacterial diversity of maize silage. The present study examined the bacterial diversity of whole-plant maize silage during fermentation (for 60 days) and subsequent aerobic exposure (from d 60 to $\mathrm{d}$ 63) by Illumina Miseq sequence platform. 


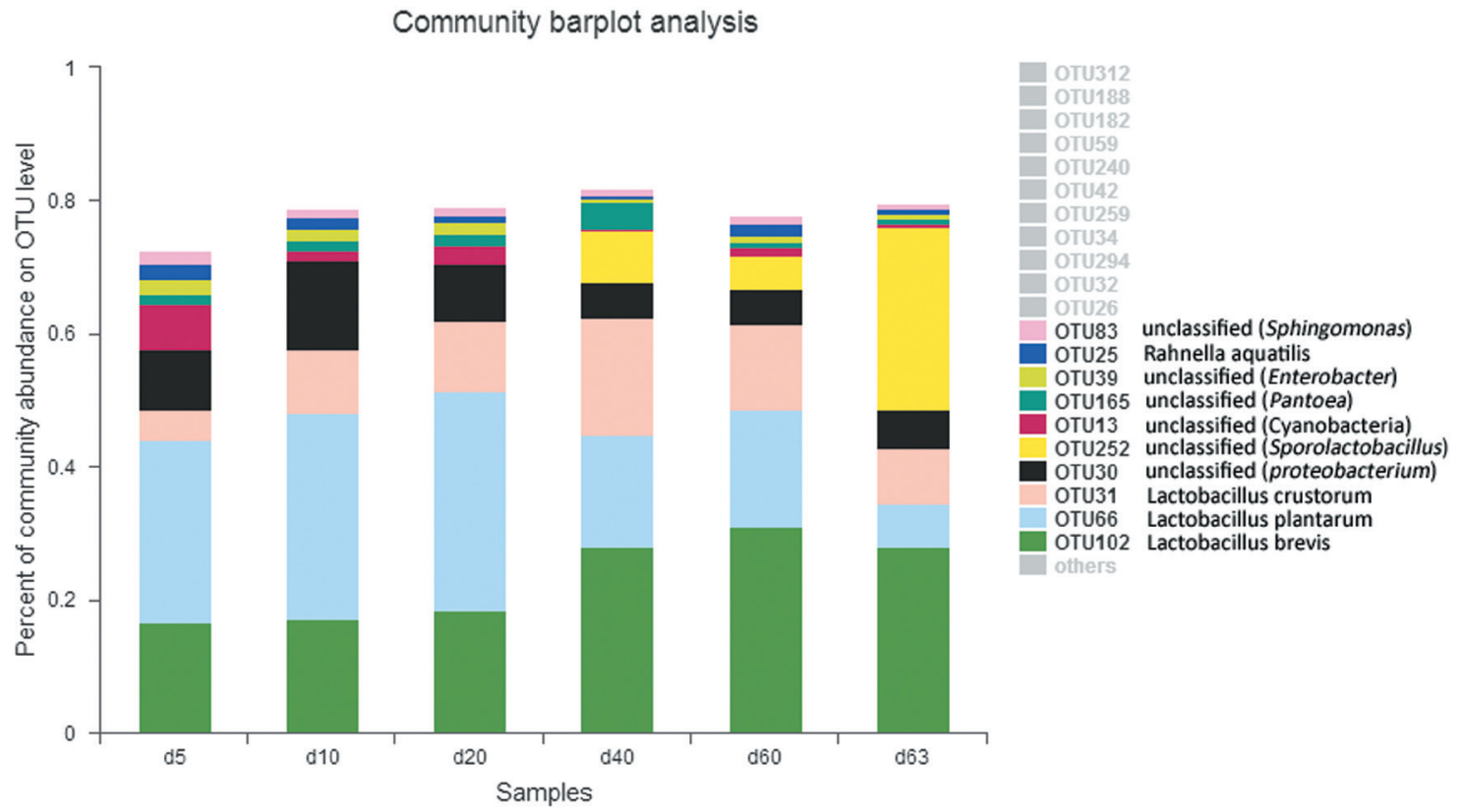

Figure 4. Relative abundance of bacterial community in maize silage during ensiling and air exposure periods at OTUs level. The most 10 common OTUs in all samples were showed. X-axis represents sample day, Y-axis represents the relative abundance. OTUs with abundance lower than $1 \%$ in samples were not shown. The species could not be assigned were marked as 'unclassified', then they were assigned at genus level or up one or more levels. OTUs, operational taxonomic units.

As known from previous studies, 5 to 7 days is a good time to check the microbial composition and biochemical index
$[5,6]$. This was verified by the $\mathrm{pH}$ value which reached below 4.0 and the rapid growth of Lactobacilus in silage after 5 days

\section{Fisher'exact test bar plot on Genus level}
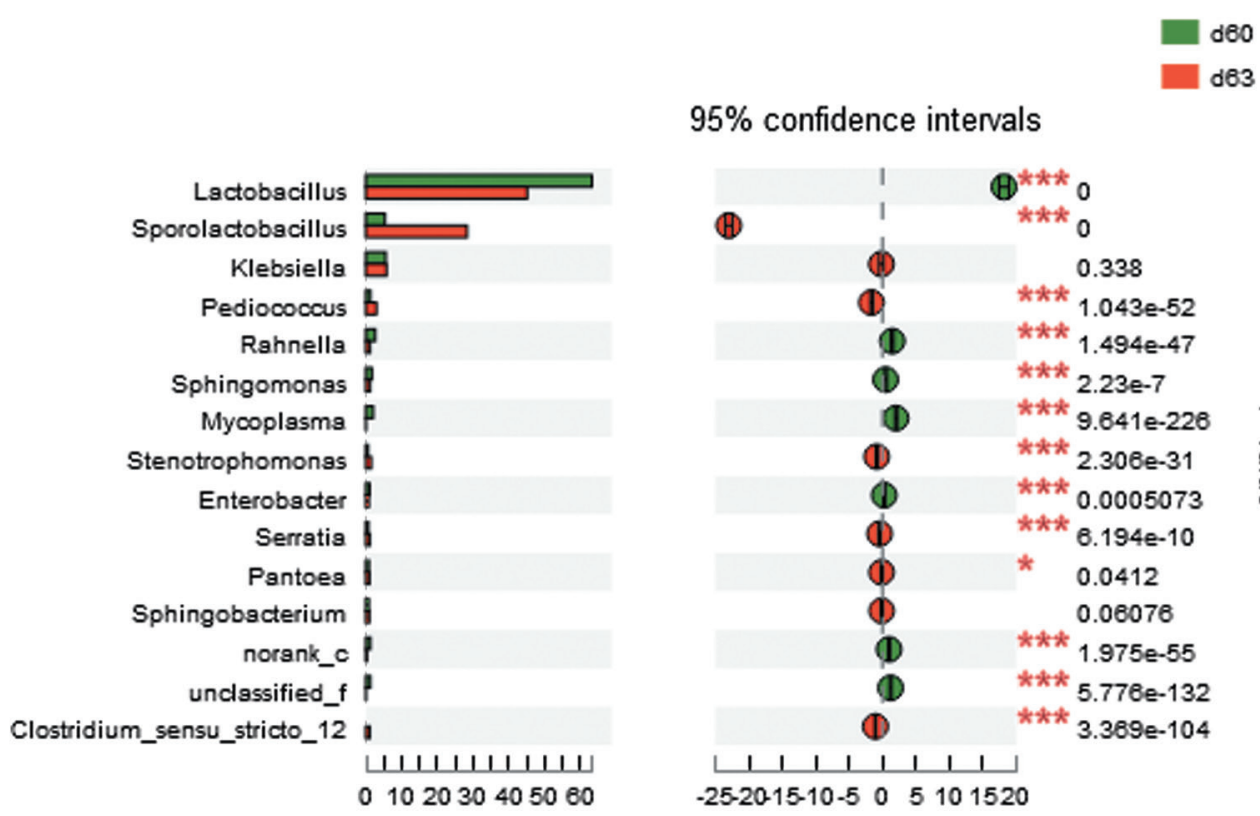

$95 \%$ confidence intervals

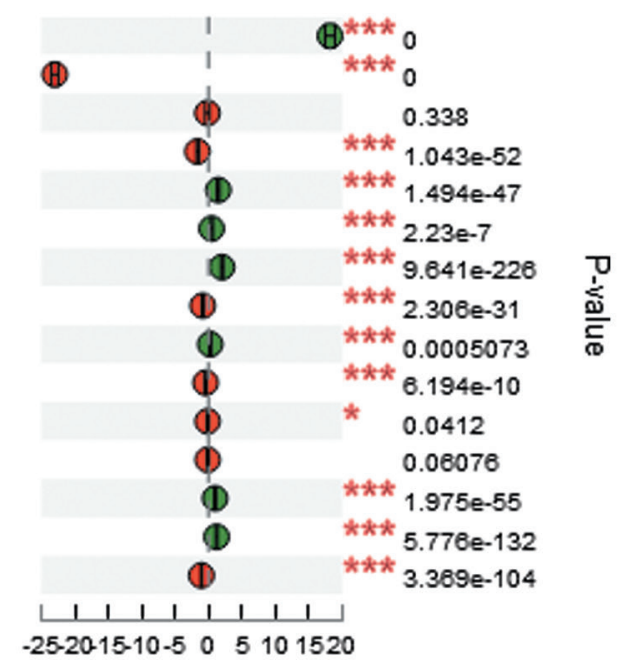

Proportions(\%) Difference between proportions(\%)

Figure 5. The comparison of silage bacterial species between end of ensiling sample ( $\mathrm{d}$ 60) and aerobic exposure sample ( $\mathrm{d}$ 63). Fisher's two-tailed tests were used to examine the difference of abundance between two samples. The X-axis in column diagram in the left indicates the abundance proportion of each bacterial species, and $Y$-axis represents bacterial species at genus level. The scatter diagram in the right indicates the difference proportion of species abundance between two samples at $95 \%$ confidence interval. ${ }^{*} p<0.05,{ }^{* *} p<0.01,{ }^{* * *} p<0.001$. 
of fermentation. For 60 days of fermentation, the $\mathrm{pH}$ remained below 4.0 stably and even after opening the package for aerobic exposure. The low $\mathrm{pH}$ value insured the anaerobic stability and eventually contributed to the favorable fermentation of whole-plant maize. Lactic acid and acetic acid, produced by $\mathrm{LAB}$, were the reason for $\mathrm{pH}$ decline [22]. In the present, the lactic acid increased significantly after 20 days of ensiling, while the significant rise of acetic acid occurred at later stage and aerobic exposure stage. Both acids have benefits for the control of spoilage yeasts or other pathogenic microorganisms [23]. During the ensiling, the content of DM dropped slightly. The content of lactic acid and acetic acid was at a high level, and the ammoniac nitrogen content was in limit ranges. All these indexes showed the excellent fermentation characteristics of the silage.

High-through sequencing has the benefit of finding more bacterial species in silage. We found 295 species belonging to 207 genera in the silages. Except 5 genera of LAB, more bacteria belong to non-LAB. It's worth noting that previous research mainly focused on LAB, or pathogenic bacteria $[5,6]$, and hardly on others which may play an equally important role during the ensiling process.

It has been well documented that the high content of LAB, such as Lactobacilus, is an assurance of rapid decline in $\mathrm{pH}$, which is a key factor ensuring fermentation quality during the ensiling process $[23,24]$. In the study, the species of Lactobacillus dominated the bacterial communities during the whole process of ensiling, even after aerobic exposure. The increasing of Lactobacillus abundance (from $49.57 \%$ in $\mathrm{d} 5$ to $63.20 \%$ in $\mathrm{d} 60$ ) displayed a positive correlation with the increasing of lactic acid (from $48.37 \mathrm{mg} / \mathrm{g}$ in d 5 to $96.9 \mathrm{mg} / \mathrm{g}$ in d 60) and acetic acid (from $4.79 \mathrm{mg} / \mathrm{g}$ to $16.87 \mathrm{mg} / \mathrm{g}$ ), indicating that the increase of lactic acid and acetic acid was mainly due to Lactobacillus. Some other studies also reported the predominance of Lactobacillus in silages [1,5,25]. Lactobacillus species, such as L. plantarum, L. brevis, and L. buchneri, are extensively used as inoculants in silage $[7,21,24,26]$. In our study, the sequences in the genus Lactobacillus were mainly assigned to $L$. plantarum, L. brevis and L. crustorum. L. plantarum, a homofermentative bacteria, produces only lactic acid, and L. brevis, hetero-fermentative LAB, produces both lactic and acetic acid. Their stable presence contributes to the rising of lactic and acetic acid during fermentations. Above all, L. crustorum was also a main constituted species of Lactobacillus during ensiling and played an important role for good fermentation quality of ensilage. Although L. crustorum has been widely reported in food fermentation, little has been reported in silage. As reported by Arasu et al [27], L. crustorum was isolated from silage, and showed high growth rates and organic acid (lactic acid, acetic acid) production capability. So, L. crustorum may be a potential probiotic for use silage.

In addition to Lactobacillus, several other acids-producing bacteria appear in the early stages ( 5 and d 10), and decrease or disappear in subsequent periods, namely Pediococcus, Lactococcus, Weissella, and Leuconostoc. This situation was demonstrated in several studies [5,25]. Pediococcus, Lactococcus, Weissella, and Leuconostoc, hetero-fermentative bacteria, can produce lactic and acetic acid. The low $\mathrm{pH}$ caused by these acids is important for initiating the fermentation of silage. These species have a role of creating a suitable environment for the further growth of lactobacilli $[21,24]$. The LAB profiles of our study are like the DGGE analysis of maize silage from Inner Mongolia which reported the dominant of Lactobacillus and the appearace of Lactococcus, Leuconostoc, and Weissella after half a year of ensiling from epiphytic bacteria [28], indicating the richness of epiphytic Lactobacillus in this region.

Gluconobacter, Acetobacter, and Flavobacterium were found in minor abundance during the early stages of ensilage. Gluconobacter and Acetobacter were reported by Gharechahi et al [25] in natural fermented maize silages. Acetobacter, an acetic acid producing and nitrogen-fixing bacteria, can be found in many plants [29], and may contributes to the $\mathrm{pH}$ decline at the early stage of silages. Flavobacterium was found in the silages and developed for inoculants because of its ability to produce cellulase [30]. Cellulase can degrade cellulose fiber to monosaccharides, such as hexose and pentose. From this point, water soluble carbohydrates or sugars were not completely illustrated the substrate available for LAB [22].

The genus Klebsiella, an epiphytic microbiota, sub-dominated the bacterial community during the entire process of ensiling. Like our findings, other studies have found that Klebsiella is present throughout the fermentation process of corn silage [7]. However, according to the report of Ni et al [31], Klebsiella was only found in pre-ensiled corn silage, not ensiling process. Most of Klebsiella species, belonging to Enterobacteriaceae family, are found to produce 1,3-propanediol during fermentation such as Klebsiella pneumoniae ATCC 8724 [32], but the propanediol and butyric acid produced by Klebsiella was not previously considered to be benefit indicators in silage [22]. In addition to the Klebsiella, other bacteria, such as Pantoea, Rahnella, Sphingomonas, Serratia, Chryseobacterium, Sphingobacterium, Stenotrophomonas, Acinetobacter, and Enterobacter, were evenly distributed throughout the fermentation process of silages in lower amounts. In fact, the above bacteria were found in various maize and grass silages $[25,30,31,33]$, but our study covered all these species for the first time. This may be related to our study methods, which cover a greater depth and breadth than other methods, or to different epiphytic bacteria of different silages. Among them, Pantoea, Rahnella, Serratia, Enterobacter, and Enterobacter belong to the family of Enterobacteriaceae which produces not only organic acids but also ethanol. Such as Enterobacter and Rahnella, they were found to produce high level of alcohol 
if they were prevalent on pre-ensiled crops [34].

Aerobic exposure had a noticeable impact on the structure of bacterial communities. In the study, the remarkable changes were the declining of Lactobacillus (from 63.20\% to 45.03\%) and the increasing of Sporolactobacillus (from 5.32\% to 28.15\%). The slightly reduction in the concentration of lactic acid may be due to the decrease of Lactobacillus. The increases in the acetic acid contents may be due to the high proportion of $L$. crustorum and L. brevis, both of which produce acetic acid. As a facultative anaerobic, Sporolactobacillus, a spore-forming, gram-positive bacterium, can produce D-lactic acids by homo-fermentation of hexoses [35]. Although the presence of Sporolactobacillus in corn silage and its antifungal activities have been reported by Kharazian et al [36], there is still little coverage of the genus in silage. In our study, Sporolactobacillus may be contributed to the maintaining of low $\mathrm{pH}$ during the aerobic exposure stage, since the silage in this period was at risk of $\mathrm{pH}$ rise due to the decreasing of LAB Lactobacillus.

Spoilage and pathogenic microorganisms may be present in silage during fermentation process, such as Clostridium, Cyanobacteria, and Listeria [37]. Listeria was not found in our study, but Cyanobacteria appeared in most of the samples (d 5, d 10, d 20, d 60). Clostridium appeared in aerobic exposure period. The species of Clostridium may be responsible for the production of butyric acid, which can reduce the content of lactic acid, as well as the production of biogenic amines by protein fermentation $[7,22]$. It may be related to Clostridium that biogenic amines increased, and lactic acid slightly decreased in aerobic exposure samples.

The term succession is defined as the biological changes of an ecosystem in a predictable way of species composition shifts [38]. The predictable dynamics of bacterial diversity were shown in our present reflected by the dominance of Lactobacillus over the whole time, indicating the good participation of this epiphytic bacterium. This agreed with other studies $[5,25]$, which reported the predominance of Lactobacillus in maize silage.

\section{CONCLUSION}

High-throughput sequencing technology revealed the diversity of the bacterial community in whole-plant maize silage. Although the bacterial community profiles varied during ensiling and aerobic exposure, Lactobacillus dominated the ensiling process, while Lactobacillus and Sporolactobacillus dominated the aerobic exposure samples. It indicated that Lactobacillus and Sporolactobacillus were the major contributors to the excellent fermentation characteristics. Other bacteria were also participated in the fermentation process. The results of this paper provide valuable information for further development and application of bacteria in silage. The underlying relationship between dynamic patterns of silage microbiota and outcome of fermentation needs further extensive studies.

\section{CONFLICT OF INTEREST}

We certify that there is no conflict of interest with any financial organization regarding the material discussed in the manuscript.

\section{ACKNOWLEDGMENTS}

This work was supported by the National Natural Science Foundation of China (NSFC) (31160474), Natural Science Foundation of Inner Mongolia Autonomous Region (No. 2018MS03022 and 2018LH03013) and First Level Training Project of Inner Mongolia Autonomous Region "Prairie Talent Project" Youth Innovation and Entrepreneur Talents.

\section{REFERENCES}

1. Zheng ML, Niu DZ, Jiang D, et al. Dynamics of microbial community during ensiling direct-cut alfalfa with and without LAB inoculant and sugar. J Appl Microbiol 2017;122:1456-70.

2. McGarvey JA, Franco RB, Palumbo JD, et al. Bacterial population dynamics during the ensiling of Medicago sativa (alfalfa) and subsequent exposure to air. J Appl Microbiol 2013;114: 1661-70.

3. Li ZH, Rui JP, Li XZ, et al. Bacterial community succession and metabolite changes during doubanjiang-meju fermentation, a Chinese traditional fermented broad bean (Vicia faba L.) paste. Food Chem 2017;218:534-42.

4. Yang L, Yang HL, Tu ZC, Wang XL. High-throughput sequencing of microbial community diversity and dynamics during Douchi fermentation. PLoS One 2016;11:e0168166.

5. Lin C, Bolsen KK, Brent BE, Daniel YCF. Epiphytic lactic acid bacteria succession during the pre-ensiling and ensiling periods of alfalfa and maize. J Appl Microbiol 1992;73:375-87.

6. Zhou Y, Drouin P, Lafreniere C. Effect of temperature $\left(5-25^{\circ} \mathrm{C}\right)$ on epiphytic lactic acid bacteria populations and fermentation of whole-plant corn silage. J Appl Microbiol 2016;121:657-71.

7. Santos AO, Ávila CLS, Pinto JC, et al. Fermentative profile and bacterial diversity of corn silages inoculated with new tropical lactic acid bacteria. J Appl Microbiol 2015;120:266-79.

8. Owens VN, Albrecht KA, Muck RE. Protein degradation and ensiling characteristics of red clover and alfalfa wilted under varying levels of shade. Can J Plant Sci 1999;79:209-22.

9. Ni K, Wang F, Zhu B, et al. Effects of lactic acid bacteria and molasses additives on the microbial community and fermentation quality of soybean silage. Bioresour Technol 2017;238: 706-15.

10.Zahiroddini H, Baah J, Absalom W, McAllister TA. Effect of an inoculants and hydrolytic enzymes on fermentation and nutritive value of whole crop barley silage. Anim Feed Sci 
Technol 2004;117:317-30.

11. Baelum J, Henriksen T, Hansen HC, Jacobsen CS. Degradation of 4-chloro-2-methylphenoxyacetic acid in top- and subsoil is quantitatively linked to the class III tfdA gene. Appl Environ Microbiol 2006;72:1476-86.

12.Dennis KL, Wang Y, Blatner NR, et al. Adenomatous polyps are driven by microbe-instigated focal inflammation and are controlled by IL-10-producing T cells. Cancer Res 2013;73: 5905-13.

13. Ma Y, Li B, Wang C, et al. 5-HTTLPR polymorphism modulates neural mechanisms of negative self-reflection. Cereb Cortex 2014;24:2421-9.

14.Edgar RC, Haas BJ, Clemente JC, Christopher Q, Rob K. UCHIME improves sensitivity and speed of chimera detection. Bioinformatics 2011;27:2194-200.

15. Quast C, Pruesse E, Yilmaz P, et al. The SILVA ribosomal RNA gene database project: improved data processing and web-based tools. Nucleic Acids Res 2013;41:590-6.

16.Schloss PD, Gevers D, Westcott SL. Reducing the effects of PCR amplification and sequencing artifacts on 16S rRNAbased studies. PLoS One 2011;6:e27310.

17.Jami E, Israel A, Kotser A, Mizrahi I. Exploring the bovine rumen bacterial community from birth to adulthood. ISME J 2013;7:1069-79.

18.Xiao Y, Li K, Xiang Y, et al. The fecal microbiota composition of boar Duroc, Yorkshire, Landrace and Hampshire pigs. AsianAustralas J Anim Sci 2017;30:1456-63.

19. Parvin S, Wang C, Li Y. Effects of inoculation with lactic acid bacteria on the bacterial communities of Italian ryegrass, whole crop maize, guinea grass and rhodes grass silages. Anim Feed Sci Technol 2010;160:160-6.

20.Li YB, Nishino N. Effects of inoculation of Lactobacillus rhamnosus and Lactobacillus buchneri on fermentation, aerobic stability and microbial communities in whole crop corn silage. Grassl Sci 2011;57:184-91.

21.Li Y, Nishino N. Monitoring the bacterial community of maize silage stored in a bunker silo inoculated with Enterococcus faecium, Lactbacillus plantarum and Lactobacillus buchneri. J Appl Microbiol 2011;110:1561-70.

22. Muck RE. Factors influencing silage quality and their implication for management. J Dairy Sci 1988;71:2992-3002.

23. Santos AO, Ávila CLS, Schwan RF. Selection of tropical lactic acid bacteria for enhancing the quality of maize silage. J Dairy Sci 2013;96:7777-89.

24. Muck R. Recent advances in silage microbiology. Agric Food Sci 2013;22:3-15.

25. Gharechahi J, Kharazian ZA, Sarikhan S, et al. The dynamics of the bacterial communities developed in maize silage. Microb
Biotechnol 2017;10:1663-77.

26. Meeske R, van der Merwe GD, Greyling JF, Cruywagen CW. The effect of the addition of a lactic acid bacterial inoculant to maize at ensiling on silage composition, silage intake, milk production and milk composition. S Afr J Anim Sci 2002;32: 263-70.

27. Arasu MV, Jung MW, Ilavenil S, et al. Characterization, phylogenetic affiliation and probiotic properties of high cell density Lactobacillus strains recovered from silage. J Sci Food Agric 2014;94:2429-40.

28. Han J, Hou XZ, Yang K, et al. Study of Lactobacillus population diversity in corn silage by PCR-DGGE in different regions of Inner Mongolia. Chin J Anim Nutr 2009;36:526-32.

29.Kumiko N, Taniguchi M, Ujike S, et al. Characterization of acetic acid bacteria in traditional acetic acid fermentation of rice vinegar (komesu) and unpolished rice vinegar (kurosu) produced in Japan. Appl Environ Microbiol 2001;67:986-90.

30. Navarretebolaños JL, Jiménezislas H, Botelloalvarez E, Ricomartínez R. Mixed culture optimization for marigold flower ensilage via experimental design and response surface methodology. J Agric Food Chem 2003;51:2206-11.

31.Ni KK, Minh TT, Tu TT, et al. Comparative microbiota assessment of wilted Italian ryegrass, whole crop corn, and wilted alfalfa silage using denaturing gradient gel electrophoresis and next-generation sequencing. Appl Microbiol Biotechnol 2017; 101:1385-94.

32. Yang X, Kim DS, Choi HS, et al. Repeated batch production of 1,3-propanediol from biodiesel derived waste glycerol by Klebsiella pneumoniae. Chem Eng J 2017;314:660-9.

33. Heron SJE, Wilkinson JF, Duffus CM. Enterobacteria associated with grass and silages. J Appl Microbiol 1993;75:13-7.

34.Li Y, Nishino N. Changes in the bacterial community and composition of fermentation products during ensiling of wilted Italian ryegrass and wilted guinea grass silages. Anim Sci J 2013;84:607-12.

35. Li JH, Sun JF, Wu B, He BF. Combined utilization of nutrients and sugar derived from wheat bran for d-Lactate fermentation by Sporolactobacillus inulinus YBS1-5. Bioresour Technol 2017; 229:33-8.

36. Kharazian ZA, Jouzani GS, Aghdasi M, et al. Biocontrol potential of Lactobacillus strains isolated from corn silages against some plant pathogenic fungi. Biol Control 2017;110:33-43.

37.Duniere L, Xu SW, Long J, et al. Bacterial and fungal core microbiomes associated with small grain silages during ensiling and aerobic spoilage. BMC Microbiol 2017;17:50.

38. Odum EP. The strategy of ecosystem development. Science 1969;164:262-70. 